\title{
Estimation of Fracture Toughness by Testing Notched Fracture Specimens and Applying the Theory of Critical Distances
}

\author{
S. Cicero, V. Madrazo, and I. A. Carrascal \\ Departamento de Ciencia e Ingeniería del Terreno y de los Materiales, Universidad de Cantabria, \\ Av/Los Castros s/n, 39005 Santander, Cantabria, Spain
}

Correspondence should be addressed to V. Madrazo, madrazov@unican.es

Received 14 June 2012; Accepted 12 August 2012

Academic Editors: C. S. Ha and P. Karjalainen

Copyright (c) 2012 S. Cicero et al. This is an open access article distributed under the Creative Commons Attribution License, which permits unrestricted use, distribution, and reproduction in any medium, provided the original work is properly cited.

This paper applies a methodology that allows the fracture toughness of a given material to be estimated by testing notched fracture toughness specimens and applying the Theory of Critical Distances, which requires the elastic stress field at the notch tip to be determined by finite elements simulation. This methodology, which is not intended to substitute any standardised fracture characterisation procedure, constitutes an alternative in those situations where pre-cracking processes may be too time-consuming, too expensive or, simply, cannot be performed. It comprises testing two notched specimens with different notch radii, defining the corresponding stress fields at fracture by using finite elements analysis, and applying the Theory of Critical Distances in order to calibrate the material's critical distance and to apply the corresponding apparent fracture toughness formulation. The methodology has been applied to two different materials, PMMA and Al7075-T651, and the results have proven that, as long as the Theory of Critical Distances has been applied within its validity range, the fracture toughness estimations are highly accurate.

\section{Introduction}

The experimental obtainment of the fracture toughness $\left(K_{c}\right)$ of a given material is generally performed following well-known international standards (e.g., [1-3]). The tests basically consist in applying an increasing quasistatic load to fracture toughness specimens (generally Compact or SingleEdge Bend specimens [1-3]) until the final fracture takes place, and the corresponding standard provides comprehensive guidance on how to proceed with the obtained test data in order to derive the fracture toughness value. The tests are, therefore, quite simple. However, these tests involve time-consuming preparation of specimens, which includes machining and, above all, fatigue precracking. The latter requires the use of dynamic machines and the careful application of variable loads until a certain crack is obtained. Any problem (e.g., overload) during the precracking process may induce excessive plasticity on the crack tip, and the specimen becomes useless.

Therefore, considering that because of these precracking processes, ordinary fracture toughness tests may be rather time consuming (and thus, expensive), requires the use of expensive, specific dynamic machines, and is susceptible to unexpected events causing the uselessness of specimens, it is here considered of interest to propose alternative fracture toughness characterisation methodologies that avoid the need for precracking processes.

With this objective and based on the notch effect observed in the material fracture resistance, a methodology is applied that estimates the material fracture toughness from notched fracture specimens, which are performed through machining and do not require precracking processes. The notch effect is analysed here using the Theory of Critical Distances (TCD), and the corresponding fracture toughness estimation requires the calculation of the stress field at the notch tip using finite elements analysis. Thus, the paper presents an introduction to both the notch effect and the TCD in Section 2, the proposed methodology is presented in Section 3, an experimental programme, together with the corresponding finite elements simulations, is outlined in Section 4, Section 5 gathers the results derived from the proposed methodology, together with the discussion, and Section 6 presents the conclusions. 


\section{The Notch Effect and the Theory of Critical Distances}

2.1. The Notch Effect on the Fracture Resistance. Notched components exhibit a fracture resistance, generally referred to as the apparent fracture toughness, which is greater than that obtained in cracked components. This is discussed here, as an example, for a notch of length $a$ and radius $\rho$ in a uniform stress $\sigma$ in an infinite body.

For brittle failure of a sharp crack, fracture mechanics establishes that the critical situation, $\sigma_{c}$, is achieved when the applied stress multiplied by the square root of the crack length is equal to a constant related to the material fracture toughness [4]:

$$
\sigma \sqrt{a}=k_{1}
$$

However, notches subject components to less critical stress fields, in such a way that (1) becomes

$$
\sigma \cdot a^{\alpha}=k_{2}
$$

where the exponent $\alpha$ is a constant. Therefore, if a fracture test is performed using a notched fracture toughness specimen and the equations provided by the standards (which are indicated for cracked specimens) are applied, the corresponding fracture resistance (apparent fracture toughness) is greater than the fracture toughness obtained from cracked specimens. Experimental evidence on this subject may be consulted in [5-12].

Moreover, there are two main failure criteria in notch theory: the global criterion and the local criterion $[8,9]$. The former establishes that fracture occurs when the notch stress intensity factor $\left(K_{\rho}\right)$ reaches a critical value $\left(K_{\rho}^{c}\right)$ which depends on the material and the notch radius:

$$
K_{\rho}=K_{\rho}^{c}
$$

where $K_{\rho}$ defines the stress and strain fields in the vicinity of the notch tip. This approach, of unquestionable significance, is totally analogous to that used in cracks, but its application is very limited because of the lack of analytical solutions for $K_{\rho}$ and/or standardised procedures for the experimental definition of $K_{\rho}^{c}$.

As regards local criteria, these are based on the stressstrain field at the notch tip and are easier to apply than global criteria from a practical point of view. Among the most important of these are the point method (PM) and the line method (LM). These two methods are actually two methodologies of the Theory of Critical Distances (TCD), which is explained in the following section.

2.2. The Theory of Critical Distances. The Theory of Critical Distances (TCD) $[5,13]$ is actually a group of methodologies, all of them using a characteristic material length parameter (the critical distance) when performing fracture (and fatigue) assessments of components containing any kind of stress risers (i.e., cracks, U-shaped notches, V-shaped notches, pores, etc.). Although it was first presented in the $1950 \mathrm{~s}[14,15]$, it has been in the last decade, driven by the use of finite elements modelling, that this theory has been systematically analysed, establishing its applicability to different types of materials (e.g., metals, ceramics, polymers, and composites), failure processes (mainly fracture and fatigue), and conditions (e.g., linear-elastic versus elastoplastic) (e.g., $[6,7,16-21])$.

The above-mentioned length parameter is usually referred as $L$ (critical distance), whose expression is (in fracture analysis)

$$
L=\frac{1}{\pi}\left(\frac{K_{\mathrm{IC}}}{\sigma_{0}}\right)^{2}
$$

where $K_{\mathrm{IC}}$ is the material fracture toughness under plane strain conditions and $\sigma_{0}$ is a characteristic material strength parameter (the inherent strength), usually larger than the ultimate tensile strength $\left(\sigma_{u}\right)$, which must be calibrated. Only in those situations where there is a linear-elastic behaviour at both the micro- and the macroscale (e.g., fracture of ceramics) does $\sigma_{0}$ coincide with $\sigma_{u}$. In fatigue analysis, $L$ has an analogous expression that may be consulted in the bibliography (e.g., [5]).

When making fracture predictions through the TCD, there are four main methodologies, all of them using $L$ together with a linear-elastic approach: two of them are based on the stress field and two are based on the stress intensity factor. In any case the predictions made by these methodologies are very similar [5]. Here, the reader is referred to $[5,22]$ for a detailed explanation of those methodologies based on the stress intensity factor (the Imaginary Crack Method and Finite Fracture Mechanics), whereas stress-fieldbased methodologies are presented in some detail. These are as follows.

(i) The Point Method (PM). This is the simplest methodology, and it assumes that fracture occurs when the stress reaches the inherent strength $\left(\sigma_{0}\right)$ at a certain distance from the defect tip, $r_{c}$. It considers linearelastic behaviour, and from the stress field in a crack tip $[5,23]$, it is straightforward to demonstrate that $r_{c}$ is $\mathrm{L} / 2$ :

$$
\frac{K_{\mathrm{IC}}}{\sqrt{2 \pi r_{c}}}=\sigma_{0} \Longrightarrow r_{c}=\frac{1}{2 \pi}\left(\frac{K_{\mathrm{IC}}}{\sigma_{0}}\right)^{2}=\frac{L}{2} .
$$

In some cases (e.g., fracture on ceramics) $\sigma_{0}$ is equal to $\sigma_{u}$, whereas in many other cases (e.g., fracture in polymers or metals), $\sigma_{0}$ is larger than $\sigma_{u}$. In any case, the inherent strength is a constant for a given material. The failure criterion is, therefore,

$$
\sigma\left(\frac{L}{2}\right)=\sigma_{0}
$$

Figure 1 presents a schema of this methodology.

(ii) The Line Method (LM). This considers that fracture occurs when the average stress along a certain distance, $d$ (starting from the defect tip), reaches the inherent strength, $\sigma_{0}$. Again, from the stress field in 


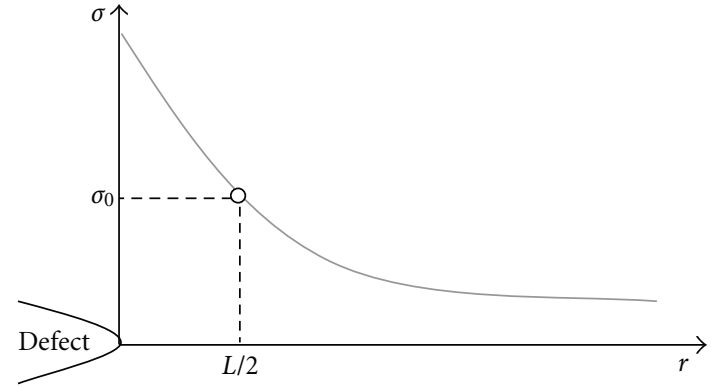

FIGURE 1: Stress-distance curve at the defect tip, and definition of the PM methodology.

a crack tip, it is easy to demonstrate that $d$ is equal to $2 L[5]$ :

$$
\begin{gathered}
\frac{1}{d} \int_{0}^{d} \frac{K_{\mathrm{IC}}}{\sqrt{2 \pi r}} d r=\frac{2}{\sqrt{2 \pi}} \frac{K_{\mathrm{IC}}}{d^{1 / 2}}=\sigma_{0} \\
\Longrightarrow d=\frac{4}{2 \pi}\left(\frac{K_{\mathrm{IC}}}{\sigma_{0}}\right)^{2}=2 L .
\end{gathered}
$$

Therefore, the LM expression is

$$
\frac{1}{2 L} \int_{0}^{2 L} \sigma(r) d r=\sigma_{0} .
$$

Both the LM and the PM [5] generate results which are reasonably similar to the experimental ones.

Moreover, both the PM and the LM provide expressions for the apparent fracture toughness $\left(K_{\mathrm{IN}}\right)$ exhibited by notched components. This has implications from a practical point of view, given that it reduces the fracture analysis in a notched component to an equivalent situation in a cracked component, with the only particularity of considering $K_{\mathrm{IN}}$ instead of $K_{\text {IC. }}$. Thus, fracture occurs when

$$
K_{I}=K_{\mathrm{IN}} \text {. }
$$

$K_{I}$ being the stress intensity factor for a crack with the same dimensions of the notch (but the radius at the tip). In the case of U-shaped notches, $K_{\mathrm{IN}}$ may be obtained from the TCD and the notch tip stress distribution provided by Creager and Paris [24], which is equal to that ahead of the crack tip but displaced a distance equal to $\rho / 2$ along the $x$-axis:

$$
\sigma(r)=\frac{K_{I}}{\sqrt{\pi}} \frac{2(r+\rho)}{(2 r+\rho)^{3 / 2}},
$$

where $\rho$ is the notch radius and $r$ is the distance existing from the notch tip to the point being assessed. If the PM is considered, (6) may be combined with (10), obtaining [5]

$$
K_{\mathrm{IN}}=K_{\mathrm{IC}} \frac{(1+(\rho / L))^{3 / 2}}{(1+(2 \rho / L))} \text {. }
$$

If the LM is considered (8) together with (10), (12) arises [5], which provides a particularly simple relation between $K_{\mathrm{IC}}$ and $K_{\mathrm{IN}}$ :

$$
K_{\mathrm{IN}}=K_{\mathrm{IC}} \sqrt{1+\frac{\rho}{4 L}}
$$

\section{Proposed Methodology for Fracture Toughness Estimation}

In order to avoid the need for precracking processes during the preparation of fracture cracked specimens, the methodology followed in this paper consists in the following steps (see Figure 2).

(1) Perform two fracture tests, following well-known fracture toughness standards, using notched fracture toughness specimens with different notch radii obtained through machining processes, such as wire electric discharge machining (WEDM). Here, it is recommended that one of the notches has the minimum possible notch radius which, in case of using a WEDM process, is that caused directly by the wire. This notch provides the closest situation possible to that existing in cracked conditions, but the resulting fracture resistance cannot be directly taken as the fracture toughness, given that extremely small radii may cause noticeable notch effects.

(2) Obtain the stress field at rupture in both specimens, generally by using finite elements. The simulation is rather simple, considering that it assumes linerelastic behaviour of the material and also that the geometry of both Compact (CT) specimens and Single-Edge-Notch Bend (SENB) specimens is very simple (it can even be parameterised, so that the geometry is obtained by entering a few dimensions).

(3) Apply the TCD (e.g., PM or LM). The application of the PM is particularly simple in this case and allows the material critical distance to be obtained, as shown in Figure 2.

(4) Apply the corresponding formulation providing the relation between $K_{\mathrm{IN}}$ and $K_{\mathrm{IC}}$. That is, in case of following the PM in Step 3, (11) should be used and (13) is obtained:

$$
K_{\mathrm{IC}}=K_{\mathrm{IN}} \frac{(1+(2 \rho / L))}{(1+(\rho / L))^{3 / 2}}
$$

$K_{\mathrm{IN}}$ being the apparent fracture toughness obtained in any of the notched specimens, $\rho$ being the corresponding notch radius, and $L$ the critical distance obtained in Step 3.

This approach has previously been proposed in [25], providing accurate results for a number of different materials. Therefore, this work intends to provide further validation on the use of the TCD for the estimation of fracture toughness.

In case of following the LM, (12) should be applied and an analogous equation to (13) will be obtained.

\section{Experimental Programme and Finite Elements Simulation}

4.1. Experimental Programme. The methodology proposed here will be applied to two experimental programmes reported, together with the corresponding results, in $[6,7]$. 

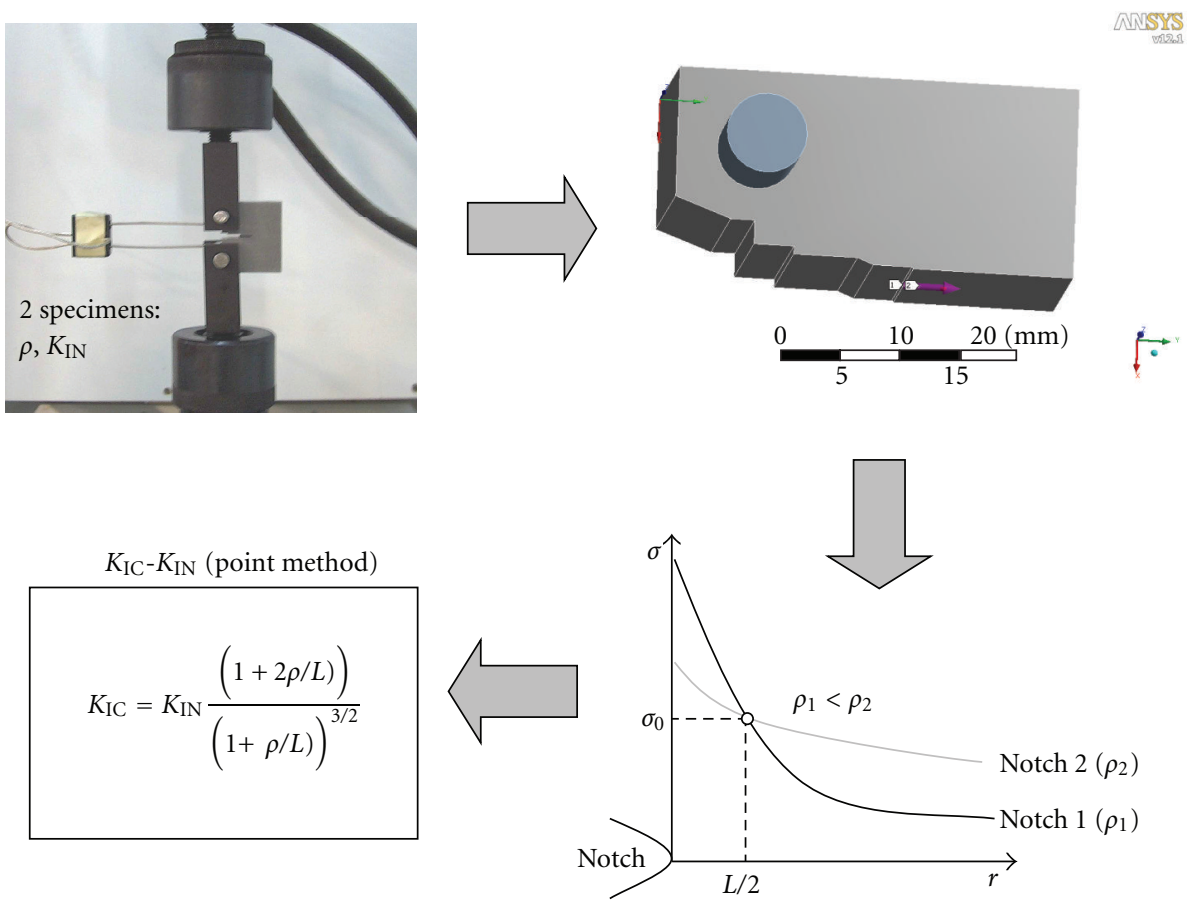

Figure 2: Scheme of the proposed methodology, comprising fracture tests, finite elements modelling, and the application of the TCD.

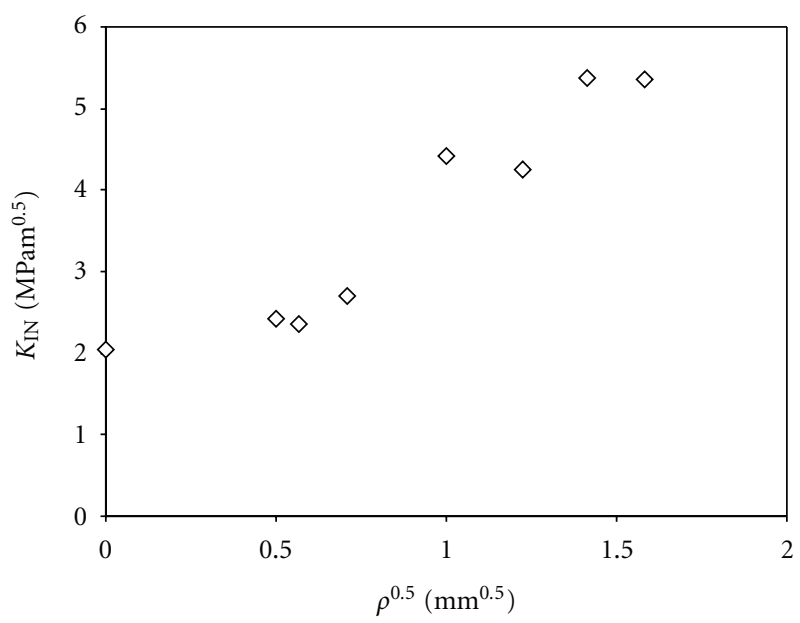

$\diamond$ Average experimental values

FIGURE 3: $K_{\text {IN }}$ average experimental results obtained in PMMA [6].

(i) In [6], fracture tests were performed on PMMA SENB specimens. A total of eight sets of tests were performed, corresponding to eight different notch radii: $0 \mathrm{~mm}$ (crack-type defects), $0.25 \mathrm{~mm}, 0.32 \mathrm{~mm}$, $0.50 \mathrm{~mm}, 1.0 \mathrm{~mm}, 1.5 \mathrm{~mm}, 2.0 \mathrm{~mm}$, and $2.5 \mathrm{~mm}$, each set being tentatively composed of five tests. The notches were performed by machining, except for those whose notch radius was close to zero, which were generated by sawing a razor blade across an initial notch root (precracking is not indicated in this type of materials). Thus, the fracture characterisation of this type of materials does not involve precracking, but the authors have deemed it to be of interest to validate the methodology on a polymer. The results for every individual test can be consulted in [6], while Figure 3 shows the results obtained for the different sets in terms of the average apparent fracture toughness value obtained for each notch radius.

(ii) In [7], fracture tests were performed on Al7075T651 CT specimens with LT orientation. A total number of 24 tests were performed, corresponding to six different notch radii: $0 \mathrm{~mm}$ (crack-type defects), $0.15 \mathrm{~mm}, 0.21 \mathrm{~mm}, 0.47 \mathrm{~mm}, 1.0 \mathrm{~mm}$, and $2.0 \mathrm{~mm}$. The notches were performed by EDM, except for the crack-type defects, which were generated by fatigue precracking. Figure 4 shows the results in terms of the average apparent fracture toughness obtained for each notch radius.

Table 1 gathers all the experimental results in terms of the average apparent fracture toughness obtained for each notch radius.

4.2. Finite Elements Simulation. The different specimens, with their corresponding notch radius, were simulated using finite elements analysis (ANSYS software [26]). The simulation basically consisted in subjecting the different types of specimens (in terms of notch radius) to their average failure load, assuming linear-elastic behaviour of the material and obtaining the stress field at rupture in the defect tip. Here, it should be noted that the mesh was performed using SOLID186 elements (3D, 20-node solid elements with quadratic displacement behaviour), the mesh being much 


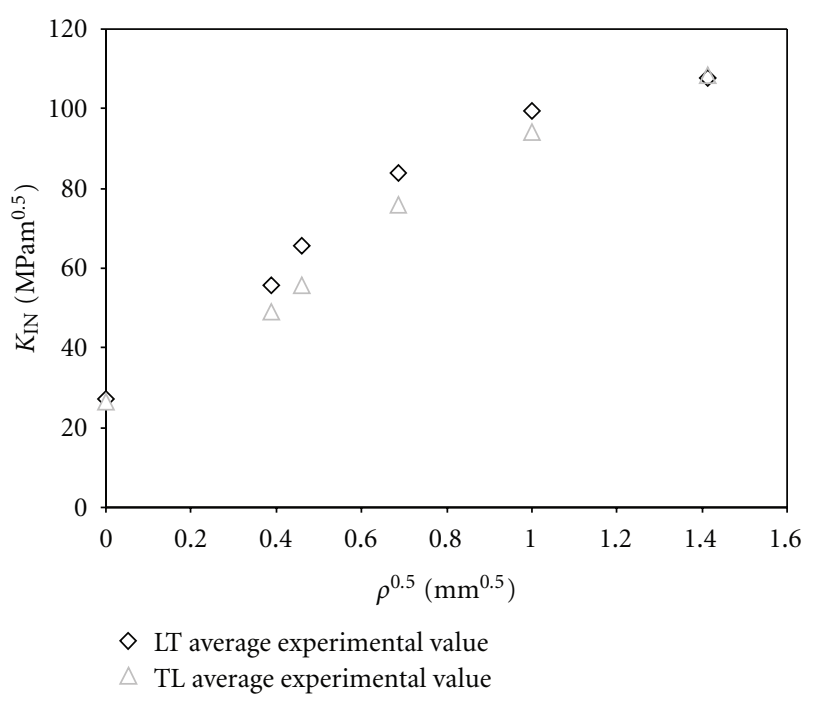

FIGURE 4: $K_{\text {IN }}$ average experimental results obtained in Al7075T651 [7].

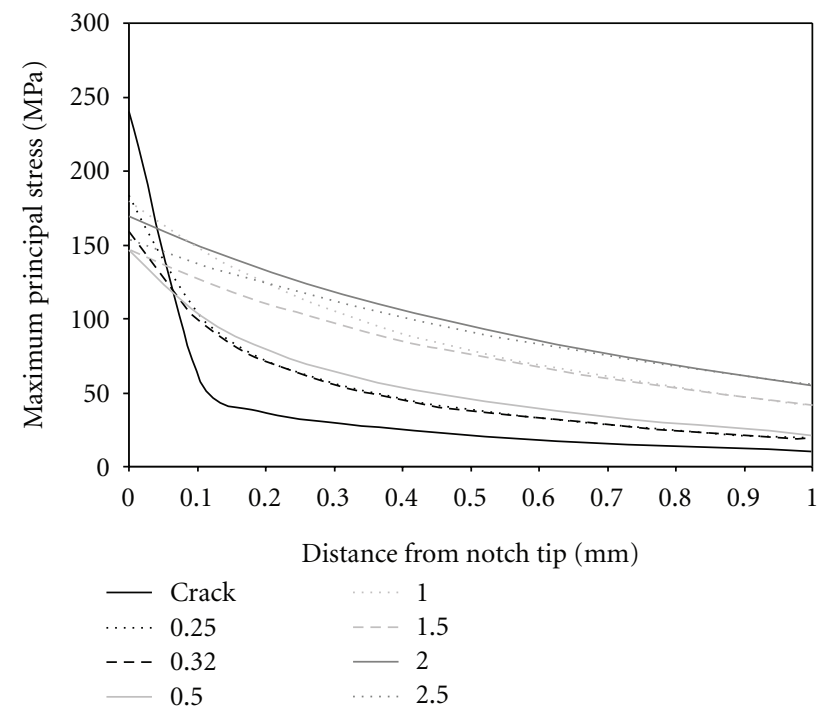

FIgURE 5: Stress-distance curves at rupture in PMMA specimens for the different notch radii.

more refined at the defect tip because of the higher gradients appearing in this zone. The element sizes resulted in the same order of magnitude as the finally obtained critical distances $[6,7]$. A detailed explanation of the simulation process can be found in $[6,7]$, while Figures 5 and 6 gather the different stress fields.

\section{Results and Discussion}

Once the tests have been performed and the stress fields have been obtained, it is now possible to apply the proposed methodology. The fracture toughness estimations are provided by (13), so the critical distance $(L)$ must be determined first. Moreover, the methodology states that only two fracture tests on notched specimens are necessary, so the possible

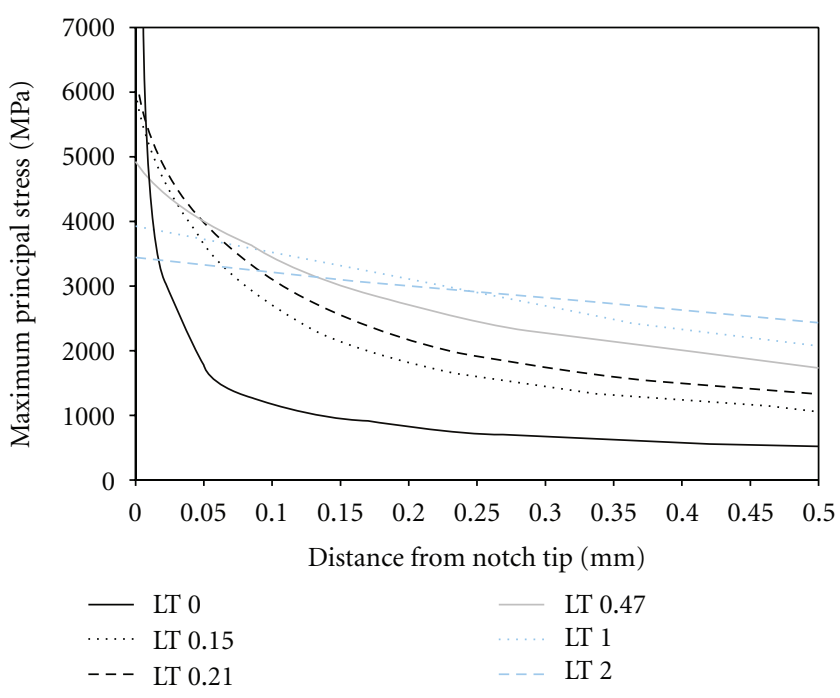

FIGURE 6: Stress-distance curves at rupture in Al7075-T651 specimens for the different notch radii.

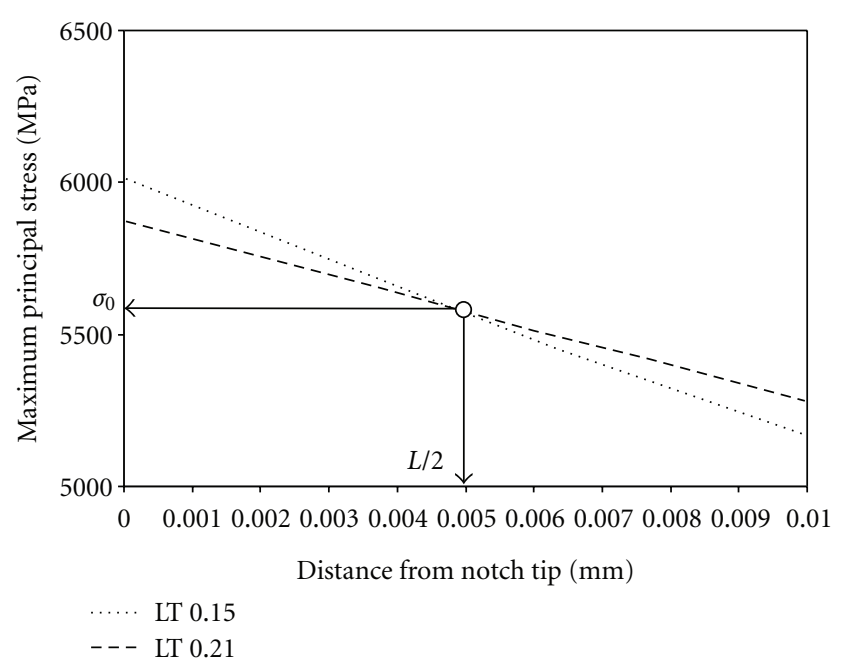

FIGURE 7: Stress-distance curves at rupture in Al7075-T651 LT specimens with notch radii of $0.15 \mathrm{~mm}$ and $0.21 \mathrm{~mm}$, and obtainment of $L$ and $\sigma_{0}$.

combinations derived from the experimental programme are rather high. For the sake of simplicity, and also because it represents a physical situation which is closer to that existing in a crack, the stress field corresponding to the notched specimens with minimum notch radius will be used in all cases $(0.25 \mathrm{~mm}$ in PMMA and $0.15 \mathrm{~mm}$ in Al7075-T651), so the estimations arise from the combination of these specimens with any other one from the list shown in Table 1. The corresponding estimations will be compared to the results obtained in the cracked specimens, whose fracture resistance is, precisely, the fracture toughness.

As an example, Figure 7 gathers the stress fields obtained for a notch radius of $0.15 \mathrm{~mm}$ (considered in all combinations, as stated above) and for a notch radius of $0.21 \mathrm{~mm}$ in Al7075-T651 LT specimens. The curves cross each other 


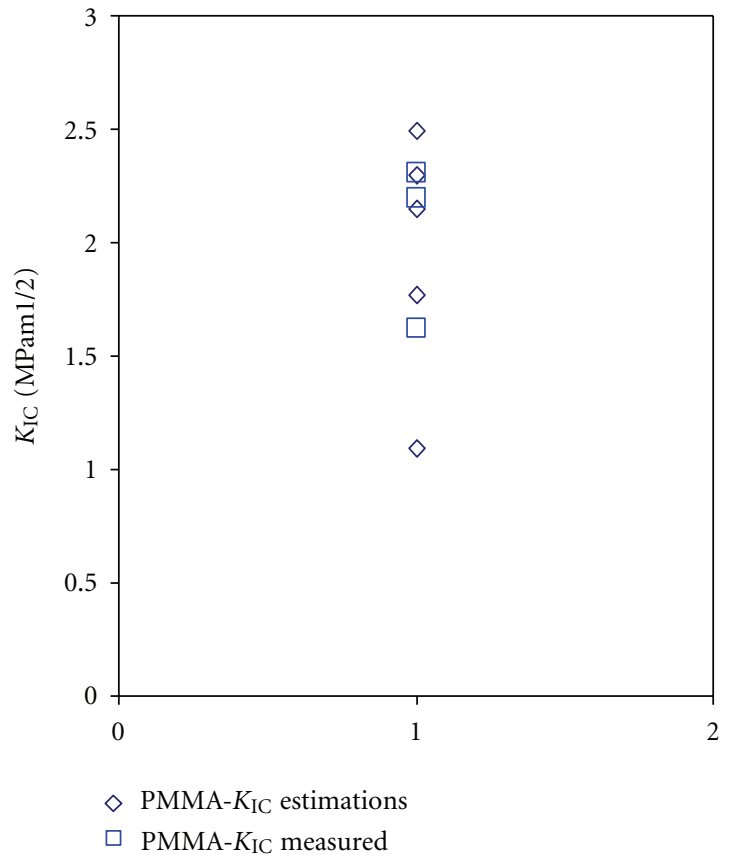

(a)

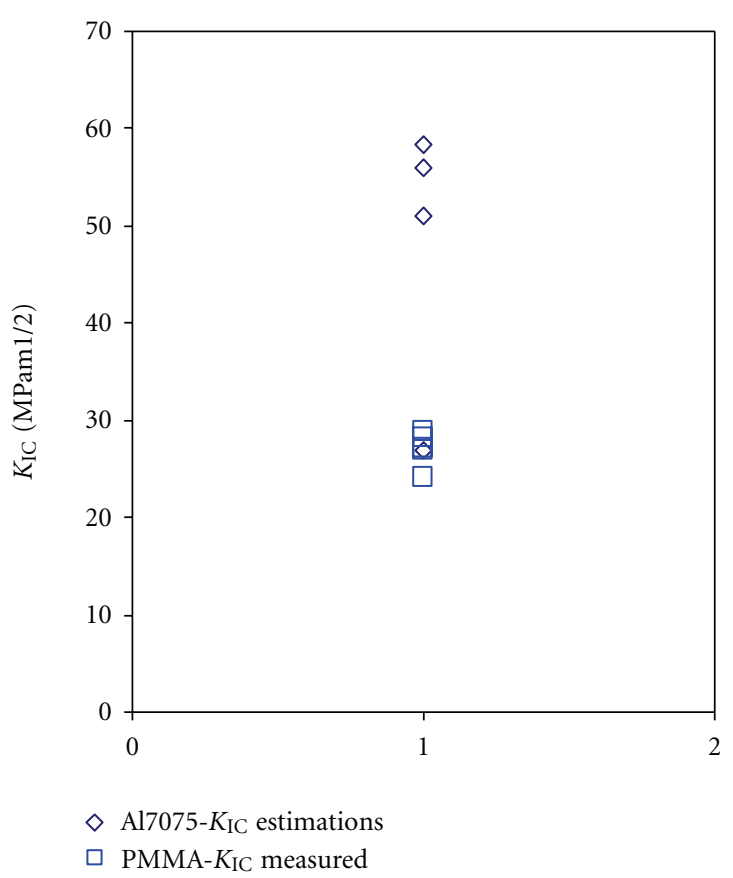

(b)

FIgure 8: Comparison between $K_{\text {IC }}$ experimental results and $K_{\text {IC }}$ estimations: (a) PMMA; (b) Al7075-T651 (TL orientation).

TABLE 1: Average apparent fracture toughness obtained for the different materials and notch radii $[6,7]$.

\begin{tabular}{|c|c|c|c|c|c|}
\hline Material & Notch radius $\rho(\mathrm{mm})$ & $K_{\mathrm{IN}}\left(\mathrm{MPam}^{1 / 2}\right)$ & Material & Notch radius $\rho(\mathrm{mm})$ & $K_{\mathrm{IN}}\left(\mathrm{MPam}^{1 / 2}\right)$ \\
\hline \multirow{8}{*}{ PMMA } & $\approx 0$ & 2.04 & \multirow{8}{*}{$\mathrm{Al} 7075$ (LT) } & $\approx 0$ & 27.01 \\
\hline & 0.25 & 2.43 & & 0.15 & 55.78 \\
\hline & 0.32 & 2.35 & & 0.21 & 65.73 \\
\hline & 0.5 & 2.71 & & 0.47 & 83.98 \\
\hline & 1.0 & 4.41 & & 1.0 & 99.43 \\
\hline & 1.5 & 4.25 & & 2.0 & 107.58 \\
\hline & 2.0 & 5.38 & & & \\
\hline & 2.5 & 5.36 & & & \\
\hline
\end{tabular}

at a point that, following the PM, defines the critical distance $(L=0.01 \mathrm{~mm})$ and the inherent strength $\left(\sigma_{0}=\right.$ $5584.5 \mathrm{MPa})$. By entering the obtained value of $L$ in (13), together with the corresponding notch radius $(\rho)$ and apparent fracture toughness $\left(K_{\mathrm{IN}}\right)$, the estimation of the fracture toughness is straightforward. Here, and again for the sake of simplicity and physical consistency, the values of $\rho$ and $K_{\mathrm{IN}}$ considered in the analysis are those corresponding to the lowest notch radius $\left(0.15 \mathrm{~mm}\right.$ and $55.78 \mathrm{MPam}^{1 / 2}$, respectively, in the example).

The process has been repeated for the different materials and combinations, providing the results shown in Table 2 and Figure 8. As shown in the table, there are no results in PMMA for the combination of 0.25 and $0.32 \mathrm{~mm}$ notch radii, the reason being that their respective stress profiles are basically coincident along the distance and separate at a certain point, without any clear crosspoint to be used in the definition of $L$. In Figure 8, all the experimental results are shown (not only the average values), together with the different predictions, in order to visualise the scatter in both the experimental results and the estimations.

In principle, the estimations obtained in PMMA are quite similar to the experimental values, although the scatter is higher, and the estimations obtained in Al7075 clearly overestimate the material fracture toughness, except for the result obtained when combining notches with $0.15 \mathrm{~mm}$ and $0.21 \mathrm{~mm}$ notch radii. This could compromise the applicability of the proposed methodology, but, on the contrary, it is consistent with the analyses performed in $[6,7,27]$. In these documents, it is shown that the TCD provides accurate results, when following its strict definition, as long as the Neuber number [28], defined as the ratio between the notch radius and the critical distance, is lower than a certain value that has been proposed to be 20 . Alternative calibration processes must be followed if it is intended to extend, in terms of the Neuber number, the range of accuracy of the TCD. 
TABLE 2: Fracture toughness $\left(K_{\mathrm{IC}}\right)$ estimations obtained by using the proposed methodology.

\begin{tabular}{|c|c|c|c|c|c|c|c|}
\hline Material & $\begin{array}{l}\text { Notch radii } \\
\text { combination }\end{array}$ & $\begin{array}{c}\rho \text { in }(13) \\
(\mathrm{mm})\end{array}$ & $\begin{array}{l}K_{\mathrm{IN}} \text { in }(13) \\
\left(\mathrm{MPam}^{1 / 2}\right)\end{array}$ & $L(\mathrm{~mm})$ & $\begin{array}{c}\text { Measured } K_{\mathrm{IC}} \\
\left(\mathrm{MPam}^{1 / 2}\right) \\
\end{array}$ & $\begin{array}{c}\text { Estimated } K_{\mathrm{IC}} \\
\left(\mathrm{MPam}^{1 / 2}\right)\end{array}$ & $\begin{array}{c}\text { Deviation from } \\
\text { measured } K_{\mathrm{IC}}(\%)\end{array}$ \\
\hline \multirow{6}{*}{ PMMA } & $0.25-0.32$ & \multirow{6}{*}{0.25} & \multirow{6}{*}{2.43} & - & \multirow{6}{*}{2.04} & - & - \\
\hline & $0.25-0.50$ & & & 0.19 & & 2.48 & 21.5 \\
\hline & $0.25-1.0$ & & & 0.014 & & 1.08 & -47.0 \\
\hline & $0.25-1.5$ & & & 0.115 & & 2.29 & 12.2 \\
\hline & $0.25-2.0$ & & & 0.046 & & 1.76 & -13.7 \\
\hline & $0.25-2.5$ & & & 0.086 & & 2.14 & 4.9 \\
\hline \multirow{4}{*}{ Al7075-T651 (LT) } & $0.15-0.21$ & \multirow{4}{*}{0.15} & \multirow{4}{*}{55.78} & 0.010 & \multirow{4}{*}{27.01} & 26.89 & 0.44 \\
\hline & $0.15-0.47$ & & & 0.060 & & 51.11 & 89.2 \\
\hline & $0.15-1.0$ & & & 0.094 & & 55.90 & 106.9 \\
\hline & $0.15-2.0$ & & & 0.132 & & 58.46 & 116.4 \\
\hline
\end{tabular}

Here, given that the precise calibration of $L$ has provided values of $0.105 \mathrm{~mm}$ in PMMA [6] and $0.015 \mathrm{~mm}$ in Al7075T651 [7], the corresponding Neuber number exceeds the value of 20 in several cases: notch radius of $2.5 \mathrm{~mm}$ in PMMA, and notch radii of $0.47 \mathrm{~mm}, 1.0 \mathrm{~mm}$ and $2.0 \mathrm{~mm}$ in case of the aluminium alloy. In fact, the Neuber numbers corresponding to these Al7075-T651 notched specimens are noticeably higher than 20 . Therefore, the only fracture toughness estimation of Al7075-T651 that has been performed within the validity range of the TCD provides a very good estimation of the fracture toughness.

Concerning PMMA, the predictions are still satisfactory, given that there is just one estimation outside the TCD validity range (obtained when considering a $2.5 \mathrm{~mm}$ notch radius) which, in any case, had provided the best estimation (its Neuber number, 23.8, is very close to the validity limit). The poor prediction obtained when combining notch radii of $0.25 \mathrm{~mm}$ and $1.0 \mathrm{~mm}$ is caused by the abnormally high fracture resistance obtained in the tests which, as explained in [6], has no physical reason and is caused by the limited amount of tests performed and the scatter associated to fracture tests in this type of material. In any case, even considering this poor result and not considering that obtained with $2.5 \mathrm{~mm}$ notch radius (outside the validity range), the average value of the fracture toughness estimation is $1.90 \mathrm{MPam}^{1 / 2}$, quite close to the experimental average value $\left(2.04 \mathrm{MPam}^{1 / 2}\right)$.

\section{Conclusion}

This paper has presented a methodology that provides estimations of the material fracture toughness without the need for testing cracked specimens, which allows the expensive time-consuming precracking process to be avoided. The methodology, which is not intended to substitute or to question standardised characterisation methodologies, proposes the testing of two notched fracture toughness specimens, the obtainment of their corresponding stress profiles on the defect tip at rupture (through finite elements modelling), and the application of the Theory of Critical distances in order to derive the fracture toughness estimation from the apparent fracture toughness measured on the notched specimens.

The methodology has been applied to two very distinct materials: polymer PMMA and aluminium alloy Al7075T651 (with LT orientation). The results, provided the TCD has been applied within its validity range, have proven that the proposed methodology provides accurate results for the two analysed materials.

\section{Acknowledgments}

The authors of this work would like to express their gratitude to the Spanish Ministry of Science and Innovation for the financial support of the project MAT2010-15721: "Análisis de integridad estructural en defectos tipo entalla", on the results of which this paper is based.

\section{References}

[1] "Metallic materials. Determination of plane-strain fracture toughness," BS EN ISO, 12737:2010, British Standards Institution, London, UK, 2010.

[2] ASTM E, "Standard test method for measurement of fracture toughness," 1820-09e1, American Society for Testing and Materials, Philadelphia, Pa, USA, 2009.

[3] "Standard test methods for plane-strain fracture toughness and strain energy release rate of plastic materials," ASTM D5045-99, American Society of Testing and Materials, Philadelphia, Pa, USA, 1999.

[4] A. A. Griffth, "The phenomena of rupture and flow in solids," Philosophical Transactions of the Royal Society A, vol. 221, pp. 163-198, 1920.

[5] D. Taylor, The Theory of Critical Distances: A New Perspective in Fracture Mechanics, Elsevier, 2007.

[6] S. Cicero, V. Madrazo, and I. A. Carrascal, "Analysis of notch effect in PMMA by using the theory of critical distances," Engineering Fracture Mechanics, vol. 86, pp. 56-72, 2012.

[7] V. Madrazo, S. Cicero, and I. A. Carrascal, "On the Point Method and the Line Method notch effect predictions in Al7075-T651," Engineering Fracture Mechanics, vol. 79, pp. 363-379, 2012.

[8] L. S. Nui, C. Chehimi, and G. Pluvinage, "Stress field near a large blunted tip V-notch and application of the concept of 
the critical notch stress intensity factor (NSIF) to the fracture toughness of very brittle materials," Engineering Fracture Mechanics, vol. 49, no. 3, pp. 325-335, 1994.

[9] G. Pluvinage, "Fatigue and fracture emanating from notch; the use of the notch stress intensity factor," Nuclear Engineering and Design, vol. 185, no. 2-3, pp. 173-184, 1998.

[10] Y. Bao and Z. Jin, "Size effects and mean strength criterion for ceramics," Fatigue \& Fracture of Engineering Materials \& Structures, vol. 16, pp. 829-835, 1993.

[11] W. Fenghui, "Prediction of intrinsic fracture toughness for brittle materials from the apparent toughness of notchedcrack specimen," Journal of Materials Science, vol. 35, no. 10, pp. 2543-2546, 2000.

[12] S. Cicero, F. Gutiérrez-Solana, and J. A. Álvarez, "Structural integrity assessment of components subjected to low constraint conditions," Engineering Fracture Mechanics, vol. 75, no. 10, pp. 3038-3059, 2008.

[13] D. Taylor, M. Merlo, R. Pegley, and M. P. Cavatorta, "The effect of stress concentrations on the fracture strength of polymethylmethacrylate," Materials Science and Engineering A, vol. 382, no. 1-2, pp. 288-294, 2004.

[14] H. Neuber, Theory of Notch Stresses: Principles for Exact Calculation of Strength with Reference to Structural form and Material, Springer, Berlin, Germany, 1958.

[15] R. E. Peterson, "Notch sensitivity", in Metal Fatigue, G. Sines and J. L. Waisman, Eds., pp. 293-306, McGraw Hill, New York, NY, USA, 1959.

[16] D. Taylor and G. Wang, "The validation of some methods of notch fatigue analysis," Fatigue and Fracture of Engineering Materials and Structures, vol. 23, no. 5, pp. 387-394, 2000.

[17] D. Taylor, "A mechanistic approach to critical-distance methods in notch fatigue," Fatigue and Fracture of Engineering Materials and Structures, vol. 24, no. 4, pp. 215-224, 2001.

[18] L. Susmel and D. Taylor, "Fatigue design in the presence of stress concentrations," Journal of Strain Analysis for Engineering Design, vol. 38, no. 5, pp. 443-452, 2003.

[19] D. Taylor, P. Bologna, and K. Bel Knani, "Prediction of fatigue failure location on a component using a critical distance method," International Journal of Fatigue, vol. 22, no. 9, pp. 735-742, 2000.

[20] L. Susmel and D. Taylor, "On the use of the theory of critical distances to predict static failures in ductile metallic materials containing different geometrical features," Engineering Fracture Mechanics, vol. 75, no. 15, pp. 4410-4421, 2008.

[21] L. Susmel and D. Taylor, "An elasto-plastic reformulation of the theory of critical distances to estimate lifetime of notched components failing in the low/medium-cycle fatigue regime," Journal of Engineering Materials and Technology, vol. 132, no. 2, pp. 0210021-0210028, 2010.

[22] D. Taylor, P. Cornetti, and N. Pugno, "The fracture mechanics of finite crack extension," Engineering Fracture Mechanics, vol. 72, no. 7, pp. 1021-1038, 2005.

[23] T. L. Anderson, Fracture Mechanics: Fundamentals and Applications, CRC Press, Fla, USA, 1991.

[24] M. Creager and P. C. Paris, "Elastic field equations for blunt cracks with reference to stress corrosion cracking," International Journal of Fracture Mechanics, vol. 3, no. 4, pp. 247-252, 1967.

[25] L. Susmel and D. Taylor, "The theory of critical distances as an alternative experimental strategy for the determination of $\mathrm{K}_{\mathrm{IC}}$ and $\Delta \mathrm{K}_{\mathrm{th}}$," Engineering Fracture Mechanics, vol. 77, no. 9, pp. 1492-1501, 2010.

[26] “ANSYS 12. 0 User's Manual," ANSYS Inc., 2009.

[27] S. Cicero, V. Madrazo, and I. A. Carrascal, "On the point method load-bearing capacity predictions in Al7075-T651 structural components containing stress risers," Engineering Failure Analysis. In press.

[28] D. Taylor, "Applications of the theory of critical distances in failure analysis," Engineering Failure Analysis, vol. 18, no. 2, pp. 543-549, 2011. 

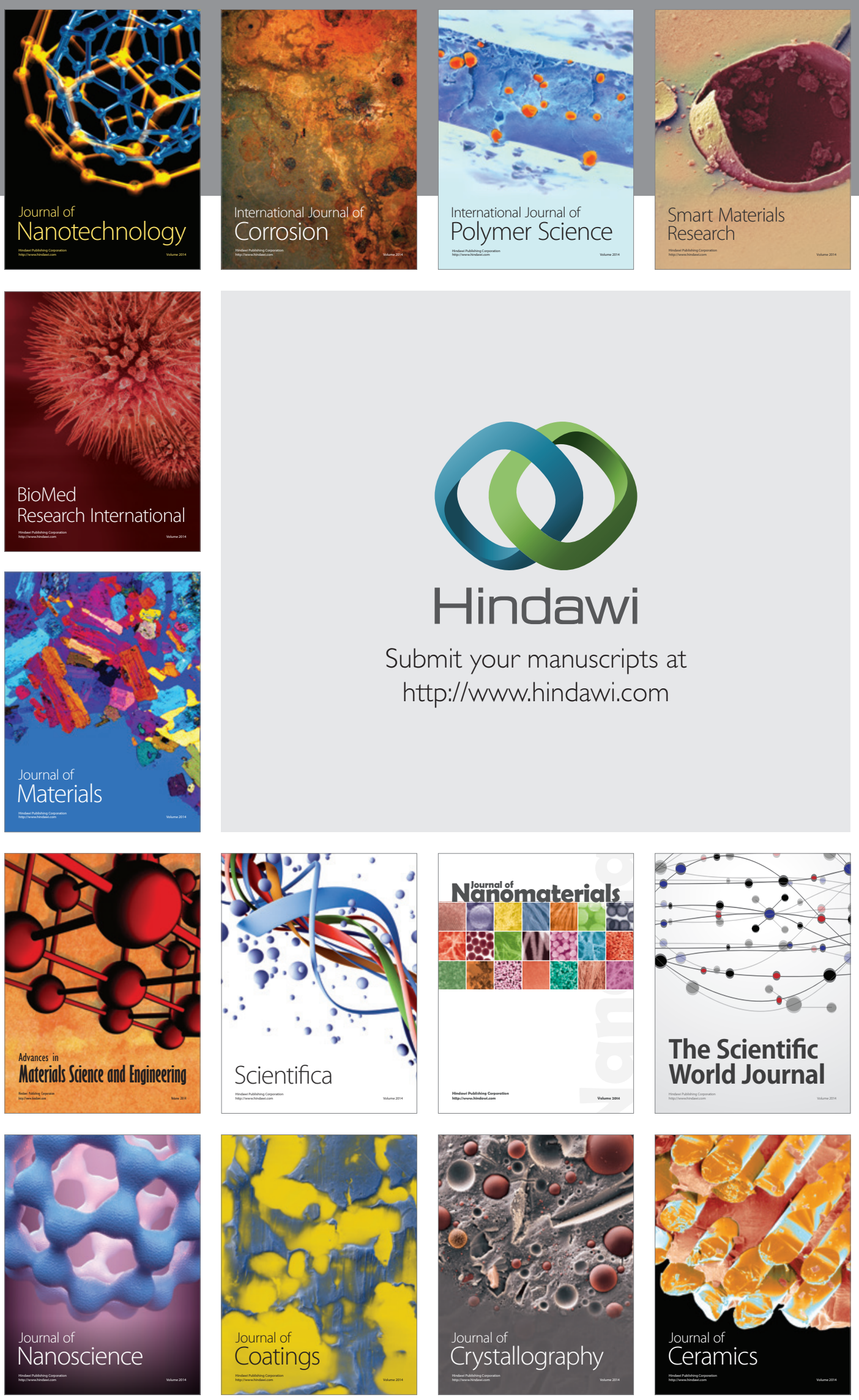

The Scientific World Journal

Submit your manuscripts at

http://www.hindawi.com

\section{World Journal}

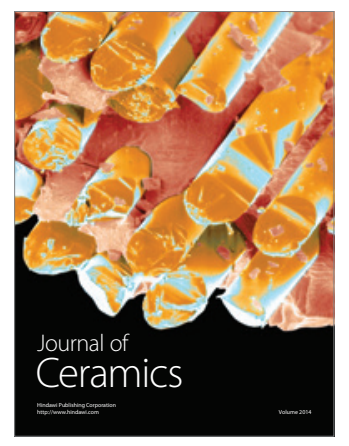

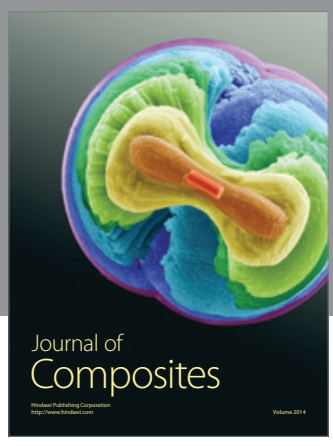
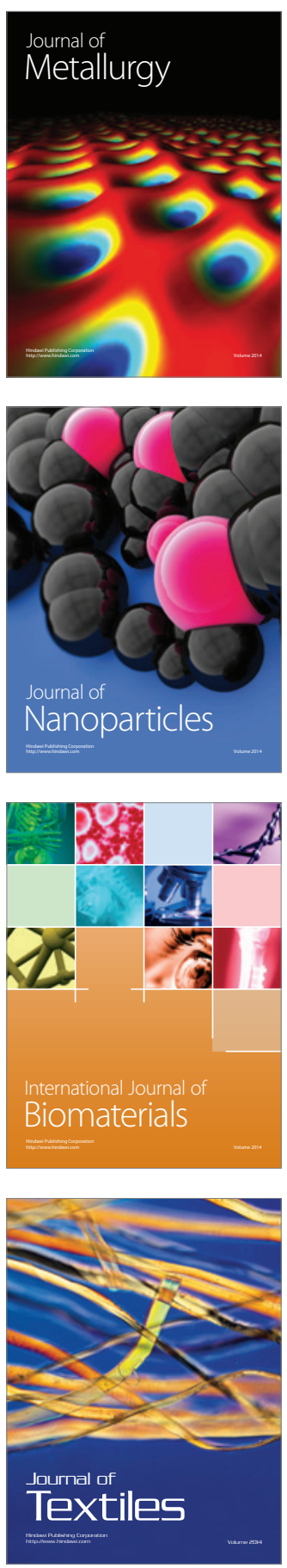